\title{
Uma adaptação operística d'As Aves de Aristófanes na Alemanha de Weimar
}

\author{
ADRIANE DA SILVA DUARTE \\ Departamento de Letras Clássicas e Vernáculas \\ Faculdade de Filosofia, Letras e Ciências Humanas \\ Universidade de São Paulo
}

\begin{abstract}
RESUMO: Este artigo propõe uma comparação entre a ópera Die Vögel de Walter Braunfels (1882-1954) e a comédia As Aves de Aristófanes (segunda metade do séc. V a.C.), que a inspirou. Se, por um lado, a retomada da comédia grega, num contexto histórico e cultural diverso, explicita sua recepção na modernidade, por outro, a escolha dessa obra especifica e as adaptações a ela propostas são significativas para que se possa compreender o período que a suscitou.

PALAVRAS-CHAVE: Comédia grega antiga; Aristófanes; As Aves; Ópera alemã; Braunfels; Die Vögel.
\end{abstract}

Apesar de ser um dos mais expressivos autores de comédia de todos os tempos, Aristófanes pouco influenciou a configuração que o gênero cômico assumiu após sua morte. Isso se explica pelas características da Comédia Grega Antiga, drama que se alimentava antes de acontecimentos cotidianos e personalidades da vida ateniense do que de tipos e situações arquetípicas, recorrentes a partir da Comédia Nova. Esse compromisso com o contexto imediato é o maior obstáculo para a sua recepção posterior, bem como para retomadas de sua obra. No entanto, quando superado, propicia uma ocasião privilegiada para que se possa captar uma visão da Antiguidade, pois não só os temas literários são evocados, mas também o ambiente político-social em que se inserem. A adaptação de Walter Braunfels (1882-1954) da comédia As Aves para ópera é um desses momentos de diálogo em que se depreende um dos sentidos que a Antigüidade assume modernamente, mais especificadamente na Alemanha da República de Weimar.

Embora Die Vögel, adaptação operística da comédia aristofânica As Aves, tenha alcançado sucesso imediato de público e crítica desde a sua estréia em 1920 na cidade de Munique, Walter Braunfels é um nome pouco conhecido na história da música. Em parte, isso se deve à sua postura reacionária, que o levou à defesa de ideais estéticos ultrapassados, sobretudo os do romantismo alemão, e à oposição às vanguardas que dominavam o cenário musical berlinense no início do século XX. Mas a razão principal para esse esquecimento 
foi a sua inclusão na lista de artistas proscritos pelo nazismo devido ao caráter degenerado de sua música, o que determinou uma interrupção abrupta em sua carreira. A princípio, isso poderia causar espanto, sobretudo quando se tem em vista o seu conservadorismo musical e a sua completa inserção nos meios oficiais, atestada por suas funções como membro da Academia Prussiana de Artes e diretor do Conservatório de Colônia. No entanto, a sua recusa em apoiar o regime e, não menos importante, as suas origens judaicas motivaram em 1933 o desligamento de seus cargos e a interdição de sua obra, o que o levou a um recolhimento forçado do qual só emergiu ao final da Guerra, em 1945, quando não havia mais lugar para a música que ele professava no país em reconstrução.

No momento da proscrição, Braunfels se viu diante do mesmo dilema das personagens da ópera que lhe trouxe a fama, o deixar ou não sua pátria. Mas, ao contrário de Evélpides e Pisetero, personagens principais d'As Aves, ele se recusou a emigrar como muitos de seus contemporâneos fizeram. Ironicamente, a razão que Braunfels apresenta na ópera para a partida dos dois atenienses de sua terra natal é a recusa de assistir passivamente a degenerescência da Arte:

E foi o motivo principal, que dos homens me afastou, a incapacidade de assistir como a Arte, grácil Arte, se degenera (die holde Kunst entartet) sobre a terra ${ }^{1}$.

Sua intenção nessa passagem era criticar a Nova Música, o que dá a sua ópera um tom de manifesto, então recurso costumeiro no debate musical ${ }^{2}$. Jamais poderia imaginar que ele próprio seria considerado um representante da "Arte degenerada" (Entartete Kunst) e muito menos que sua ópera viria a ser gravada pela primeira vez por um selo Entartete Musik, da Decca, dedicado a resgatar as obras suprimidas pelo Terceiro Reich.

A turbulência que leva à estagnação de sua carreira também marca a composição de Die Vögel. A ópera foi escrita durante seis anos, entre 1913 e 1919, coincidindo com um período especialmente complexo da história alemã: primeira guerra mundial, fim do Império e proclamação da República de Weimar, tudo isso entremeado por distúrbios civis e greves operárias. O país que entra em guerra em 1914 dela sai irreconhecível quatro anos depois. As disputas que se delineavam antes, eclodem ao seu final. É um tempo de posições acirradas, mas também, de certezas abaladas. O mundo mudou tanto em um intervalo tão breve que se justifica o longo tempo demandado para conclusão da obra.

O próprio Braunfels exemplifica bem a extensão dessas mudanças. Patriota e antipacifista, vê na guerra a oportunidade de afirmação da grandiosidade da pátria e engajase na defesa do nacionalismo alemão. Como consequêencia da derrota, converte-se ao cato-

1 Braunfels, W. Die Vögel, 1996, p. 58. Tradução da autora.

2 Por exemplo, o opúsculo de Busoni, Entwurf einer neuen Ästhetik des Tonkunst (Esboço de uma nova estética da arte musical), de 1906, com reedição em 1916, ou os panfletos de Pfitzner, Futuristengefahr (O Perigo Futurista), de 1917, e Die neue Ästhetik der musikalischen Impotenz. Ein Verwesungssymptom (A Nova Estética da impotência musical. Um sintoma da decomposição), de 1920, entre outros. 
licismo em 1918, passando a compor quase que exclusivamente sobre temas religiosos. E como tudo isso coincide com o período de composição da ópera, é de se esperar que ela também tenha sido afetada pelas vicissitudes enfrentadas por seu autor.

Em primeiro lugar, cabe perguntar por que compor uma ópera a partir de uma comédia aristofânica e, especialmente, o porquê da escolha d'As Aves. Tomar uma peça teatral como ponto de partida para um libreto é óbvio dada a natureza dramática da ópera, certamente a forma artística moderna mais próxima do teatro antigo por reunir palavra, música e dança. Além disso, a literatura e a mitologia clássicas estão ligadas à ópera desde as suas origens, bastando mencionar L'Orfeo e ll Ritorno d' Ulisse in Patria de Claudio Monteverdi (15671643), peças que são consideradas inaugurais do novo gênero e cuja inspiração grega salta aos olhos. Desde então, os exemplos se multiplicam. Interessa aqui sobretudo lembrar as incursões nesse campo de Richard Strauss (1864-1949), talvez o contemporâneo que mais influenciou a obra operística de Braunfels. Espécie de eminência parda no cenário musical do Império, Strauss compõe sobre temas clássicos Elektra (1908), cujo libreto de Hofmannsthal é bastante fiel à tragédia sofocleana, Ariadne auf Naxos (1912) e Helene von Aigypte (Helena do Egito, 1923-1927). Braunfels, que também se valerá desta temática em Galathea (1924-1929), escolhe, numa perspectiva mais carnavalizada, uma comédia grega como ponto de partida, mas, como ficará claro mais adiante, confere-lhe um final um tanto sombrio.

A escolha de Aristófanes não foi casual e certamente justifica-se, ao menos em parte, pela evidência em que o comediógrafo se encontrava no século XIX, expressa em uma sólida tradição de traduções de sua obra na Alemanha. A primeira versão integral de suas comédias, de Johann Heinrich Voss, data de $1821^{3}$. Quatro décadas depois, as obras completas de Aristófanes em alemão já somam sete, o que é um feito de qualquer ângulo que se examine. Nenhum outro autor grego ou romano, cuja obra seja comparável à comédia aristofânica no grau de dificuldade proposto, teve tantos tradutores em um tão curto intervalo na Alemanha e, arrisco o palpite, em qualquer outro país. Além disso, todas estas traduções foram impressas e as edições venderam bem, de forma que algumas chegaram a ser republicadas em menos de uma década (Werner, 1975, p. 475). Se isso não é um índice de popularidade, certamente atesta bem o interesse que sua obra suscitava então.

Esse interesse se devia principalmente a dois motivos. Por um lado, há a valorização da comédia grega antiga pelos românticos, sobretudo pelos irmãos August e Friedrich Schlegel que nela ressaltavam o vigor criativo e a presença da Fantasia, o que favoreceu sobremaneira a recepção, em especial, d'As Aves. Nessa comédia as alusões à cidade de Atenas e à sua política são menos evidentes do que nas demais e seu enredo explora os elementos fantásticos decorrentes da relação entre deuses, homens e pássaros. Entre os seus admiradores declarados estavam Goethe, que adaptou o primeiro ato para o público de Weimar em 1780, e Heine, que afirmou a sua superioridade sobre as demais em poema de 1844. Alguns, como Humbolt, chegaram a traduzir passagens seletas somente para o deleite de amigos incapazes de ler fluentemente o grego, entre eles, segundo as más línguas, Goethe e Schiller (Werner, 1975, p. 460). Por outro lado, o século XIX assistiu a uma mudança de

3 Note-se que não estou me referindo à tradução de peças isoladas, que se iniciou muito antes, em 1613, com As Nuvens de Isaak Fröreisen (Werner, 1975: 464 e 474). 
perspectiva no âmbito dos Estudos Clássicos que culminou com a revisão da imagem de inocência sublime da Antigũidade, na qual Aristófanes não se encaixava bem. A busca de uma visão mais concreta da realidade grega chamou a atenção sobre o comediógrafo e seu teatro. Naturalmente, também contribuiu para esse resgate o clima revolucionário das décadas de trinta e quarenta, que propiciou uma leitura política das comédias aristofânicas.

Alguns desses elementos exerceram, ao meu ver, papel chave na opção de Braunfels por As Aves. Em primeiro plano, está a admiração do músico pelo idealismo romântico, que não se restringia unicamente ao campo musical. De fato, o seu libreto explora a atmosfera fantástica, irreal, do reino dos pássaros, que, como foi visto, já fora notada pelos principais nomes deste movimento filosófico-literário. Assim, o compositor caracteriza os pássaros como "seres intermediários da doce fantasia" (Zwischenreich der süssen Phantasie, 1996, p. 130), por exemplo. Em texto introdutório a sua obra, Braunfels reconhece que se deixou levar pela mística da noite, cara aos poetas românticos como Novalis ou Einchendorff, afastando-se do modelo antigo (Haas, 1996: 25).

Há também a musicalidade inerente ao texto, sugerida já pela presença do coro de aves. Aristófanes põe-na em evidência pelo amplo emprego da onomatopéia, que mimetiza o cantar variado dos pássaros, como ocorre, por exemplo, na Monodia da Poupa (As Aves, v. 227-262). Para Pintacuda (1982, p. 61), autor que estuda a música no teatro aristofânico, esta comédia reúne "os mais belos cantos líricos" e representa "um novo ciclo na mélica aristofânica" em que se observa a influência das novas tendências musicais de seu tempo, expressas na adoção de formas livres e na polimetria na composição lírica. Braunfels não foi nem o primeiro nem o último compositor a se deixar seduzir. No século XIX, o grego Constantine Agathofrona Nikolopoulos (1786-1841) musicou As Aves ${ }^{4}$; já no XX, a mesma comédia inspirou o francês Jean Français a compor um dueto para dois sopranos e quarteto de cordas (1934) e o inglês Granville Bantock a escrever uma Ouverture (1946).

O momento histórico certamente exerceu também sua influência sobre a escolha de Braunfels. Embora, em seu libreto, ele descaracterize as motivações políticas que conduzem as personagens ao exílio voluntário, basicamente a indignação com o crescente poder dos tribunais sobre a vida dos indivíduos, e atribua a sua insatisfação a questões de fundo estético, há vários pontos em comum entre os períodos em que foram compostas a comédia e a ópera, mesmo que separados por tantos séculos. Quando Aristófanes encena As Aves em 414 a.C., Atenas vivia a antevéspera da expedição à Sicília, uma operação militar ousada que, ao deslocar a guerra para fora do continente, visava a conquistar importantes territórios a oeste e, assim, a consolidar a liderança política da cidade sobre a Grécia e seus vizinhos. Como atesta Tucídides, um clima eufórico tomou conta dos cidadãos que anteviam o sucesso da estratégia. As Aves pode ser vista como um comentário, irônico, é verdade, desse otimismo desenfreado, já que retrata como um ateniense, Pisetero, funda uma cidade aérea e lidera os pássaros numa guerra contra os deuses, sagrando-se, ao seu final, o ser mais poderoso do universo. Braunfels, por sua vez, inicia a composição de Die Vögel em 1913, quando todas as condições que levaram à deflagração da Primeira Guerra Mundial já se apresentavam. Os alemães viviam o

4 Até onde eu saiba, a obra integral permanece inédita, mas uma versão parcial pode ser encontrada em Music of Greek Antiquity de Petros Tabouris. 
mesmo estado de espírito que os atenienses, crentes de que o conflito viria atestar sua própria superioridade sobre as demais nações. A ópera, então o gênero musical dominante (19101915), espelha essa euforia expansionista que precede a adesão entusiasta do país à luta (Huynch, 1998, p. 23). Por tudo isso, dentre as comédias de Aristófanes, As Aves é a mais apropriada para traduzir o ânimo dos alemães nesse período e não parece crível que Braunfels tenha menosprezado esse aspecto. Afinal, em sua apresentação da obra, o compositor lembra seus ouvintes de que "tudo não passa de um jogo, de uma alegoria" (Haas, 1996, p. 33).

No entanto, assim como as coisas não saíram conforme planejaram os gregos, a malograda expedição siciliana tendo-se convertido numa das principais razões da derrota ateniense na Guerra do Peloponeso, a participação alemã na Primeira Guerra também frustrou as expectativas nacionais, acarretando a destruição da autoconfiança então reinante. Mas, se o comediógrafo grego levou sua peça ao palco antes do desastre, o compositor alemão ainda não concluíra a sua quando assistiu à derrota do seu país e à mudança de ânimo que afetou seus compatriotas. Já apontamos anteriormente o quão traumática foi, para ele, essa experiência, a ponto de determinar a passagem da fé judaica para a católica como antídoto para superar a crise moral e espiritual que se abate sobre a Alemanha. O público que comparece à estréia de Die Vögel em 1920, apenas dois anos após o fim do conflito externo, pois internamente a situação ainda era instável, embora estivesse mais carente de diversão do que nunca, também estava mais amargurado do que aquele que Braunfels tinha em mente quando, no começo da década anterior, lhe ocorrera a idéia do projeto. Nesse contexto, uma adaptação mais fiel do texto grego, com seu final apoteótico, deixa de fazer sentido e precisa ser revista. Isso é perceptível no fato de que as principais modificações introduzidas pelo compositor estão concentradas no segundo ato da ópera, permanecendo o primeiro bastante próximo do texto aristofânico. Ou seja, a medida em que a derrota se tornava palpável, maiores eram as alterações necessárias para viabilizar a obra.

O primeiro ato se distancia da comédia de Aristófanes ao apresentar como motivo da excursão campestre dos dois atenienses, Ratefreund (Pisetero ou Bom de Lábia) e Hoffegut (Evélpides ou Tudo Azul), o desencanto com a vida cultural e amorosa de Atenas e não a mania dos tribunais alegada no texto grego. Onde se lia (vv. 36-45 $)^{\text {s: }}$ :

Não odiamos aquela cidade pelo que ela é:

grande por natureza, feliz

e comum a todos que pagam taxas.

As cigarras, por um mês ou dois,

cantam sobre os ramos, mas os atenienses

cantam sempre sobre as tribunas, a vida toda.

Por isso fazemos esta caminhada

com uma cesta, uma panela e coroas de mirto, vagamos, em busca de um lugar tranqüilo, onde pousar e passar a vida;

Cf. Aristófanes. As Aves. Tradução, introdução, notas e glossário de Adriane da Silva Duarte. São Paulo: HUCITEC, 2000. 
lê-se:

Foi a malícia das mulheres que me afastou dos seus bailados frios e hostis. Talvez, aqui no reino dos alegres cantores aéreos, eu encontre uma amiga sensível, calorosa e fiel, e também mais bela do que os sombrios filhos da terra e desprovida de sua maldade. (Hoffegut em Die Vögel, 1996, p. 56);

e também:

Viemos da grande cidade, admirada por todos, onde a Arte alimenta o povo e todas as Musas devem dar seu sangue. [...] Queremos ficar contigo, aprender teu doce canto que nos entusiasma, aproveitar tudo que tens a nos dar (Ratefreund em Die Vögel, 1996, p. 66).

Essa ênfase na Arte e no Amor em seu estado puro se concretiza na figura da Rouxinol, que Braunfels torna a personificação do Sublime e alça a um dos papéis principais n'As Aves, desprovida de falas, expressava-se unicamente pela sonoridade da flauta e seu poder de sedução a tornava objeto de desejo sexual. Cabe a ela a execução do prelúdio que abre a ópera, em que se apresenta o reino dos pássaros e suas promessas de alegria e bemestar. Ao mesmo tempo em que seu canto exemplifica o poder balsâmico da Arte, também tem a capacidade de despertar as lembranças dolorosas, marcada no mito grego no pranto continuado de Procne pela morte de seu filho Ítis. Com esse lamento inicia-se o segundo ato, em que a ave e Hoffegut protagonizam uma cena romântica sem paralelos no teatro grego. Sua voz atrai o homem, despertando nele os sentimentos mais puros. Os dois se unem num dueto amoroso à luz da lua, capaz de revelar a essência do universo. O personagem, que na versão grega é pouco mais do que um bufão, fica marcado por essa experiência e assume uma dimensão ética superior, sendo o primeiro a reconhecer o erro em que Ratefreund induz todos.

Ainda na ópera, a Rouxinol, assim como as outras aves, se alinham com seu rei, a Poupa, na defesa do plano de Ratefreund: construir uma cidade aérea e sitiar os deuses, conforme dita o enredo original. Mas, diferentemente da comédia, há uma voz discordante, a da águia. Pássaro associado a Zeus, a águia faz uma curta aparição no primeiro ato com intuito de advertir os revoltosos que sua opção pela aliança com os homens, presos por sua natureza à terra, os afastaria dos deuses, habitantes das alturas (1996 p. 88).

A intervenção da águia antecipa um tema que será desenvolvido no segundo ato e que constitui a maior diferença da ópera de Braunfels em relação à comédia de Aristófanes: o do castigo divino. À maneira do teatro cômico, As Aves encerra-se com um cortejo festivo que celebra a vitória dos pássaros - na verdade, de seu líder ateniense -, sobre os deuses. Um acordo assegura a Pisetero a mão da jovem Soberania, personificação do poder absoluto. Com isso, ele se torna o novo soberano do universo, ocupando o trono deixado por Zeus.

Se na comédia grega os homens levam a melhor, na ópera eles e seus sócios alados são punidos por sua audácia. A advertência da águia é secundada pela de Prometeu, que atua de forma oposta à delineada por Aristófanes. Em As Aves, ele é o amigo dos homens, a 
quem antes havia revelado o segredo do fogo, sendo, por isso, punido de forma brutal por Zeus. Explica-se assim seu interesse ver os deuses destronados. Graças às suas informações, Pisetero negocia com a embaixada divina de forma a obter para si a mão de Soberania, antes acompanhante de Zeus. Em Die Vögel, Prometeu é o exemplo vivo do castigo. Tendo sofrido na pele as consequiências de afrontar a divindade, empenha-se para alertar homens e, especialmente aves, a evitar cometer o mesmo erro. São palavras suas (1996: 130, 134, 136):

Sou seu amigo, vim lhes alertar. Zeus dorme, já que vocês não podem compreender de outra maneira, pensem que ele dorme. Ele se voltou para outro lado, breve, ele não quer olhar... Está lhes dando tempo, crianças, para refletir. [...] Desistam, crianças, ainda há tempo. Zeus pode perdoálos, a mim também o Eterno perdoou, ele que no alto, em sua bondade, reina sobre todos os reis. [...] Pobres, pobres de vocês, Zeus está acordado! Seu castigo se aproxima.

O Zeus que emerge da fala de Prometeu não lembra em nada o Senhor do Olimpo grego, é um deus cristão, que concentra em suas mãos o perdão e o castigo. Sua ira se abate sobre os revoltosos em forma de uma tempestade diluvial, que abate os ânimos mais aguerridos. As Aves se encerra com o louvor de Pisetero, o novo ocupante do trono sagrado (vv. 1748-1765):
Ó grande luz áurea do relâmpago!
Ó lança imortal, porta-fogo
de Zeus! Ó ctônios trovões
de eco surdo e porta-chuvas,
com os quais sacode a terra.
Após tudo dominar,
obteve também Soberania, a companheira de Zeus.
Hímen, ó himeneu! [...]
Aiê, aiê, iê peão!
Viva o vencedor, ó
divindade suprema!

De forma muito diversa, Die Vögel celebra a supremacia de Zeus (1996: 142-144):

\author{
Zeus é grande! É poderoso! \\ Sua magnificência supera tudo! É magnífico! [...] \\ Deixe-nos celebrá-lo, deixe-nos louvá-lo, \\ Cante sua glória eterna! \\ Louvado seja, celebrado seja! Graças lhe sejam rendidas!
}

Os pássaros retornam para as árvores e os homens para a cidade. Ratefreund, volta como veio, inalterado. Lamenta não o ato ímpio que cometeu, mas a perda de tempo que 
essa aventura lhe acarretou e anseia pela vida urbana e seus confortos. Hoffegut, transformado pela experiência amorosa, lamenta a separação e sabe que dificilmente haverá um lugar para ele na cidade, mas que tampouco poderá viver no campo. Resta-lhe o consolo de tê-la vivido. Esse final amargo condiz melhor a experiência alemã do pós-guerra do que a festa com que se encerra a comédia ateniense.

Assim, podemos concluir que as modificações que Braunfels levou a cabo em sua adaptação d'As Aves para ópera buscam fundamentalmente enfatizar os elementos românticos ou adequá-la aos seus ideais, seja enfatizando elementos preexistentes, compatíveis com esse espírito, seja criando outros a ele apropriados, e responder às necessidades que seu próprio contexto histórico impunha ${ }^{6}$.

\section{Referências Bibliográficas}

ALMEIDA, Jorge Mattos Brito de. Música e Verdade. A estética crítica de Theodor Adorno. Tese de doutoramento apresentada ao Departamento de Filosofia, FFLCH/USP, em junho de 2000.

ARISTÓFANES. As Aves. Bilingüe. Tradução de Adriane da Silva Duarte. São Paulo: Hucitec, 2000.

BRAUNFELS, Walter. Die Vögel. London: Decca/Entartete Musik, 1996, p. 50-149.

HAAS, Frinthjof. Die Vögel: gefeiert, geächtet, rehabilitiert, vergessen. In BRAUNFELS, W. Die Vögel, London: Decca/Entartete Musik, 1996, p. 29-34.

HUYNCH, Pascal. La musique sous la République de Weimar. Paris: Fayard, 1998.

PINTACUDA, Mario. Interpretazioni musicali sul teatro di Aristofane. Palermo: Palumbo, 1982.

WERNER, Jürgen. Aristophanes-Übersetzung und Aristophanes-Bearbeitung in Deutschland. In NEWIGER, H-J. (ed.). Aristophanes und die alte Komödie. Darmstadt: Wissenschaftliche Buchgesellschaft, 1975, p. 459-485.

\section{Discografia}

BRAUNFELS, Walter. Die Vögel. Solistas (Kwon, Wottrich, Kraus, Holzmair, Görne), Rundfunkchor Berlin, Deutsches Symphonie-Orchester Berlin, direção de Lothar Zagrosek. London: Decca/Entartete Musik (448 679-2), 1996.

NIKOLOPOULOS, Konstantine A. Fragment from Birds by Aristophanes. In TABOURIS, Petros. Musik of Greek Antiquity. Atenas: F.M.Records/Paian (653), s/d.

6 Agradeço a Jorge Mattos Brito de Almeida por ter chamado minha atenção sobre a ópera de Braunfels e por suas valiosas indicações bibliográficas. 
DUARTE, Adriane da Silva. Singing Birds. An opera version of Aristophanes' Birds in Weimar Republic. Classica, São Paulo, 15/16, p. 259-267, 2002/2003.

ABSTRACT: This paper compares Die Vögel, a modern opera written and scored by the german composer Walter Braunfels (1882-1954) to its aristophanic model, the comedy Birds (second half of the fifth century b.C). Besides discussing the contemporary significance of Greek comedy, recreated in a completely different cultural and historical context (Weimar's Republic), it investigates the specific reasons for this particular choice (adapting Birds, among all Aristophanes' plays) and the resulting alterations.

KEYWORDS: Ancient Greek Comedy; Aristophanes; Birds; German opera; Walter Braunfels; Die Vögel. 